attempted to get closer for a better look. The pigeon was very timid and flew to another Caragana hedgerow. After several glimpses of the bird it finally landed on a barbed wire fence about 20 $m$ in front of me. The view this time was from the rear and to one side. The white neck band and yellow bill with a black tip were easily seen. ${ }^{2}$ When the pigeon flew the broad gray tail band was evident.

I left the schoolyard and returned 10 minutes later to attempt a photograph. The bird was still very shy and only glimpses of it were seen as it flushed from hedgerow to hedgerow. It finally flew across a stubble field to a farm yard approximatley $2 \mathrm{~km}$ to the west and was not seen again.

When I returned to Regina later that day I reported the sighting to several people in Regina. As a result Fred Lahrman drove to Herbert on 22 June but was unable to locate the bird.

According to Salt and Salt the Bandtailed Pigeon is easily mistaken for its domesticated relative but the Bandtailed is a woodland species and is more likely to be found perching in trees than the Domestic Pigeon. ${ }^{3}$

There are three previous records of sightings of the Band-tailed Pigeon in Saskatchewan: 6 August 1970 at Valley Centre near Rosetown by Wayne and Don Renauld, in Saskatoon on 30 September 1970 by Shelagh Aldous, and 28-29 June 1980 near Mortlach by B. Forbes. 1

HOUSTON, C. S., M.I. HOUSTON and J. B. GOLLOP. 1981. Saskatchewan Bird Species - Hypothetical and Rejected. Blue Jay 39(4): 196-201.

${ }^{2}$ ROBBINS, C. S., B. BRUUN, H.S. ZIM and A. SINGER. 1966. Birds of North America. Golden Press, New York. 340 pp.

${ }^{3}$ SALT, W. R., and J.R. SALT. 1976. The birds of Alberta. Hurtig, Edmonton. 498. pp.

\section{EFFECTS OF A LATE MAY BLIZZARD}

AUSTIN FORSYTH, Apt. 197, 325 - 5th Ave., Saskatoon, Saskatchewan. S7K 2P7

The morning of 29 May 1982 dawned rather hesitantly to reveal a record breaking ten $\mathrm{cm}$ of wet snow around our Pike Lake cabin. After locating a recently retired parka and boots, I set out on a tour of inspection, and found that the unseasonable weather was playing havoc with some of our resident birds.

Clumps of ten foot high berry bushes on the back slope had been flattened by the weight of the snow, and three pairs of Yellow Warblers who had nested in them were darting back and forth in complete confusion. Two pairs of robins seemed equally upset. I knew that the nest of one pair was in the fork of a poplar that was still upright, but now it was filled to the top with slush. This disrupted occupancy of nests seemed to increase the number of visiting magpies, and we have since found an unusual number of punctured eggs on the ground.

It was interesting to watch the behaviour of half a dozen Red-winged Blackbirds who had established territorial claims along the reed covered lakefront. These noisy neighbors had been following their usual springtime pattern, with the males arriving about a week before their drab brown mates. In the interval they had flown hundreds of flashy forays to protect their claims, but for several days before the storm there had been relative peace on the waterfront. The late snowfall had evidently upset this pattern, for they went back to squabbling over their territories as though their biological clock had been set back a couple of weeks. It was at least two days before the status quo was re-established. 
Veeries are common in the aspen forest that surrounds us, but seldom do they spend much time in our clearing. The snow must have interfered with their normal feeding, because that morning I counted ten of them pecking for worms in the small flower bed on the lee side of the cabin. When the snow melted we found four dead.

Most disturbing of all was the plight of hundreds of Tree Swallows who had been darting gracefully in the sky over the lake following an abundant first hatch of mosquitoes and gnats. One pair had leased the bird box that Reg Plumb has provided for our front yard, and all seemed to be going well with their nesting procedure; then came the snow, which continued intermittently for most of the day. At the top of the hill dozens of swallows were flying only a few feet from the ground, their wings heavy, and their food supply washed from the sky. Hopefully some of them made their way north westward where the storm was less severe, but I suspect that their local population has been severely depleted. Sightings to mid June in our neighborhood are almost non-existent. Even a lush new crop of mosquitoes has not brought them back, and our swallow house is vacant for the first time in eight seasons.

\section{MUSEUM PROGRAM REQUIRES INFORMATION}

The Saskatchewan Museum of Natural History is setting up a system for recording sightings and locations of all Saskatchewan flora and fauna. These data will help the Museum determine the distribution and habitat of plants and animals in the province. To increase the accuracy of these records, the Museum is seeking the assistance of the public in obtaining this information.

Of primary interest are phenomena such as snake hibernacula, bird nesting locations, concentrations of fossils, populations of turtles, breeding concentrations of amphibians, sights of rare or unusual mammals or plants and bird migration dates and locations.

Any information on plants or animals which will contribute to the knowledge of range and habitat are also welcome. Even sightings within the normal range of a species will provide information on precise locations and habitat requirements. All reports must contain date, time of day, exact location, observer's name, and any other pertinent information.

Anyone who is interested is invited to participate. Reports should be sent to the Life Sciences Unit, Saskatchewan Museum of Natural History, Wascana Park, Regina S4P 3V7. 